\title{
Medievalista
}

\section{Culhwch ac Olwen como texto de transición de la materia artúrica}

Culhwch ac Olwen as a Transitional Text within the Arthurian Matter

Luciana Cordo Russo

\section{(2) OpenEdition}

\section{Journals}

Edición electrónica

URL: http://journals.openedition.org/medievalista/1332

DOI: 10.4000/medievalista.1332

ISSN: 1646-740X

Editor

Instituto de Estudos Medievais - FCSH-UNL

Referencia electrónica

Luciana Cordo Russo, «Culhwch ac Olwen como texto de transición de la materia artúrica »,

Medievalista [En línea], 22 | 2017, Puesto en línea el 01 diciembre 2017, consultado el 30 abril 2019.

URL : http://journals.openedition.org/medievalista/1332 ; DOI : 10.4000/medievalista.1332

(C) IEM 
Título / Title: Culhwch ac Olwen como texto de transición de la materia artúrica / Culhwch ac Olwen as a Transitional Text within the Arthurian Matter

Autor(es) / Author(s): Luciana Cordo Russo

Universidade / University: Universidad Nacional de San Martín, Escuela de Humanidades

Faculdade e Departamento / Unidade de Investigação - Faculty and Department /

Research Center: Instituto Multidisciplinario de Historia y Ciencias Humanas -

CONICET

Código Postal / Postcode: C1083ACA

Cidade / City: Buenos Aires

País / Country: Argentina

Email Institucional / Institutional email: lucordorusso@yahoo.com.ar

Fonte: Medievalista [Em linha]. Direc. Bernardo Vasconcelos e Sousa. Lisboa: IEM.

Disponível em:

http://www2.fcsh.unl.pt/iem/medievalista/MEDIEVALISTA22/russo2204.html

ISSN: 1646-740X

Data recepção do artigo / Received for publication: 10 de Novembro de 2016

Data aceitação do artigo / Accepted in revised form: 22 de Fevereiro de 2017 


\section{Resumo}

Culhwch ac Olwen, relato en prosa escrito en galés medio c. 1150, recoge, bajo el marco del motivo de "La hija del gigante" proveniente del cuento tradicional, una serie de temas y episodios artúricos pertenecientes a las tradiciones literarias y legendarias que circulaban en Gales sobre la figura de este famoso personaje. Por un lado, Arturo aparece en clave heroica, es decir, con una serie de atributos que lo asimilan con la representación que recibe en algunos poemas galeses, en los que aparece como jefe de una banda de guerreros que lucha contra seres sobrenaturales. Por otro lado, en cambio, Arturo es "jefe de los príncipes de esta isla", posee una corte renombrada y dispone celosamente de costumbres y valores. Esta corte funciona también como marco narrativo para el despliegue de aventuras y como espacio privilegiado para su relato, y aloja un elenco estable de guerreros.

Por todo lo anterior, este trabajo se propone analizar la figura de Arturo, de su corte y de sus guerreros como punto de transición de la leyenda artúrica. Se intentará mostrar que al carácter ya polifacético de Arturo se suma un aspecto que prenuncia al rey de la literatura cortés, de modo que se combinan aquí rasgos heroicos, que caracterizan primitivamente al personaje, con otros que podríamos denominar protocorteses.

Palavras-chave: materia artúrica; Culhwch ac Olwen; poesía artúrica antigua; Arturo; literatura cortés.

\section{Abstract}

Culhwch ac Olwen is a Middle Welsh prose tale dated to c. 1150 that combines, within the traditional motif of the "Giant's Daughter", a series of Arthurian themes and episodes from the legendary and literary traditions known in Wales about Arthur. On the one hand, Arthur is depicted in a heroic tone, that is, with a set of attributes that tend to characterise him in early Welsh poems, in which he appears as the leader of a band of warriors who fight supernatural creatures. On the other hand, Arthur is "chief of the princes of this island", he possesses a renowned court, and jealously guards customs and values. His court also provides the narrative frame for adventures and the set for their retelling, as well as housing a stable cast of warriors.

Medievalista online N 22 | Julho - Dezembro 2017 (c) IEM - Instituto de Estudos Medievais 2 www2.fcsh.unl.pt/iem/medievalista 
Therefore, this paper seeks to analyse the figure of Arthur, his court and his warriors as a stage of transition in the Arthurian legend. It will be argued that an aspect that foreshadows the king of courtly literature is added here to the multifaceted character of Arthur. For this reason, this tale combines the heroic traits that characterises the primitive Arthur with others that could be called proto-courtly.

Keywords: Arthurian matter; Culhwch ac Olwen; Early Welsh Poetry; Arthur; courtly literature. 


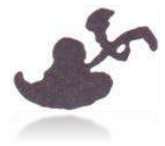

\section{Culhwch ac Olwen como texto de transición de la}

\section{materia artúrica / Culhwch ac Olwen as a Transitional Text within the Arthurian Matter}

\section{Luciana Cordo Russo}

\section{Introducción: las tradiciones artúricas galesas y Culhwch ac Olwen ${ }^{1}$}

El propósito de este trabajo consiste en estudiar la figura de Arturo, de sus guerreros y de su corte en el relato galés Culhwch ac Olwen atendiendo a la posición transicional que ocupa en la historia literaria de la materia artúrica. Se intentará mostrar que al carácter ya polifacético de Arturo (presente en un conjunto de textos vernáculos y latinos galeses) se suma un aspecto que prenuncia al rey de la literatura cortés, de modo que se combinan aquí rasgos heroicos, que caracterizan primitivamente al personaje, con otros que podríamos denominar protocorteses. De esta forma, Culhwch ac Olwen se plantea como un punto de inflexión respecto del desarrollo ulterior de la materia artúrica tanto continental como insular ${ }^{2}$. Por lo tanto, en las siguientes páginas se ofrecerá un recorrido del relato, se estudiarán los temas y motivos más significativos que comparte con las tradiciones previas, y se sistematizarán algunas diferencias encontradas con ellas que lo vuelven, justamente, un texto de transición.

\footnotetext{
${ }^{1}$ Una versión preliminar de este trabajo fue leída en las XV Jornadas Internacionales de Estudios Medievales y XXV Curso de Actualización en Historia Medieval, Buenos Aires (Argentina), septiembre de 2016. Agradezco a todos los presentes por sus observaciones, en especial a la Dra. Lidia Amor, quien leyó y revisó cuidadosamente la ponencia y, de este modo, realizó comentarios muy valiosos. La redacción final del artículo no hubiera sido posible sin el generoso subsidio de la School of Welsh, Cardiff University, que me permitió concretar una estancia de investigación en esta universidad en septiembre-octubre 2016. Vaya también mi sincero reconocimiento a los lectores anónimos por sus sugerencias.

${ }^{2}$ No será posible extenderse en este punto, i.e., los diferentes tratamientos de la materia artúrica en lengua francesa, sobre el cual existe una vasta bibliografía crítica de excelente calidad, por lo que remitimos, a título de ejemplo, a RÉGNIER-BOHLER, Danielle - "Préface". in RÉGNIER-BOHLER, Danielle (dir.) La légende arthurienne: le Graal et la Table Ronde. Paris: Laffont, 1990, pp. I-LII; BURGESS, Glyn; PRATT, Karen (ed.) - The Arthur of the French. The Arthurian Legend in Medieval French and Occitan Literature. Cardiff: University of Wales Press, 2006; AURELL, Martin - La légende du roi Arthur 5501250. París: Perrin, 2008, especialmente a partir del capítulo 7.
} 
Las tradiciones galesas sobre Arturo, tanto en latín como en lengua vernácula, son múltiples, y aquí solo podré referirme muy brevemente a ellas ${ }^{3}$. En primer lugar, en la Historia Brittonum y en los anales galeses representa al guerrero cristiano británico que combate contra los conquistadores, mientras que las mirabilia relatan historias onomásticas locales relacionadas con él ${ }^{4}$. En segundo lugar, en las vitae (Vita Cadoci de Lifris, Vita Carantoci, Vita Iltuti, Vita Paterni, Vita Gildae de Caradoc de Llancarfan) aparece como representante del poder temporal al que se enfrenta el santo de turno ${ }^{5}$. Los poemas, por su parte, nos presentan una gran variedad de facetas de Arturo, desde soldado ideal a superhéroe sobrenatural, además de como héroe que regresará para salvar a los britanos de la opresión ${ }^{6}$, hecho que se vincula con la diversidad de tipos, temas y propósitos de las composiciones mismas. En el poema heroico Y Goddodin, por caso, si bien Arturo aparece apenas mencionado, parece encarnar el valor máximo del ideal de guerrero expresado en el texto. En Preiddeu Annwn, "Los despojos de Annwn", se utiliza como excusa una expedición de Arturo al otro mundo, que tiene como fin liberar a un guerrero y adquirir un caldero mágico, para desplegar el saber literario y la habilidad versificatoria del poeta. Por último, en Pa gwr yw’r porthawr?, “¿Qué hombre es el guardia de la entrada?", Arturo busca ganar acceso a una corte custodiada por Glewlwyd Gafaelfawr, "el de Gran Puño", y debe probar su valía y la de sus hombres: es retratado aquí como el jefe de una banda de guerreros que va por el mundo combatiendo criaturas sobrenaturales (como un gato gigante o brujas); la atmósfera es

\footnotetext{
${ }^{3}$ Los investigadores que han tratado este tema son JONES, Thomas - "The Early Evolution of the Legend of Arthur" (trad. Gerald Morgan). Nottingham Medieval Studies 8 (1964), pp. 3-21; BROMWICH, Rachel - "Concepts of Arthur". Studia Celtica 10 (1975-1976), pp. 163-181 y "Celtic Elements in Arthurian Romance: a General Survey". in GROUT, P. et alii (ed.) - The Legend of Arthur in the Middle Ages. Studies presented to A. H. Diverres. Woodbridge: Brewer, 1983, pp. 41-55; JARMAN, A. O. H. - "The Delineation of Arthur in Early Welsh Verse". in VARTY, Kenneth (ed.) - An Arthurian Tapestry: Essays in Memory of Lewis Thorpe. Glasgow: Glasgow University French Department for the British Branch of the International Arthurian Society, 1981, pp. 1-21; KNIGHT, Stephen - Arthurian Literature and Society. New York: Palgrave, 2002, pp. 1-37; PADEL, Oliver - Arthur in Medieval Welsh Literature. Cardiff: University of Wales Press, 2000.

${ }^{4}$ Para una reciente revisión crítica de la idea de un Arturo histórico véase HALSALL, Guy - Worlds of Arthur. Oxford: Oxford University Press, 2013. Excelentes estudios son los de CHARLES-EDWARDS, Thomas - "The Arthur of History". in BROMWICH, Rachel; JARMAN, A. O. H.; ROBERTS, Brynley The Arthur of the Welsh. The Arthurian Legend in Medieval Welsh Literature. $2^{\mathrm{da}}$ ed. Cardiff: University of Wales Press, 2008, pp. 15-32 y HIGHAM, N. J. - King Arthur. Myth-Making and History. London y New York: Routledge, 2002. Huelga decir que en este artículo nos interesa únicamente la representación literaria de Arturo.

${ }^{5}$ Todas composiones del sigo XII; las vitae Cadoci, Gildae y Paterni son anteriores a 1130. Véase PADEL, Oliver - Arthur in Medieval Welsh Literatures, pp. 38-47.

${ }^{6}$ JONES, Thomas - "The Early Evolution of the Legend of Arthur"; KNIGHT, Stephen - Arthurian Literature and Society, p. 8.
} 
bastante cómica y desenfadada ${ }^{7}$. Todos estos ejemplos, junto con la evidencia de las Tríadas de Bretaña, indican que en el transcurso de la Alta Edad Media una serie de historias folclóricas, hechos heroicos y leyendas locales fueron asociados a Arturo, dando forma a la leyenda ${ }^{8}$. Culhwch ac Olwen, por su parte, comparte muchos elementos con todos estos textos ya que se inscribe dentro de estas tradiciones, pero también introduce diferencias notorias que encontrarán un eco en la textualidad artúrica posterior. En este sentido, este trabajo busca problematizar afirmaciones del tipo "Arthur is depicted according to the conventions of the heroic tradition of Celtic Britain as a battle-leader who has assembled around him a great many names from this same tradition" "9 puesto que se intentará demostrar el carácter multifacético de la figura artúrica.

Culhwch ac Olwen es conocido como el relato artúrico en prosa más antiguo redactado en una lengua vernácula, cuya puesta por escrito ha sido datada c. 1150 por las investigaciones filológicas más recientes ${ }^{10}$. Esta fecha, que sitúa la versión existente del

\footnotetext{
${ }^{7}$ Sobre este poema véase SIMS-WILLIAMS, Patrick - "The Early Welsh Arthurian Poems". in BROMWICH, Rachel; JARMAN, A. O. H.; ROBERTS, Brynley - The Arthur of the Welsh, pp. 33-71. Para un panorama general respecto de las referencias a Arturo en este y en otros poemas conservados en el mismo manuscrito, véase JARMAN, A. O. H. - "The Arthurian Allusions in the Black Book of Carmarthen". in GROUT, P. et alii (ed.) - The Legend of Arthur in the Middle Ages, pp. 99-112. Sobre "Los despojos de Annwn" véase HIGLEY, Sarah - Preiddeu Annwn: The Spoils of Annwn [en línea]. in LUPACK, Alan; LUPACK, Barbara (dir.) - The Camelot Project. Rochester: University of Rochester, 2007. Disponible en http://d.lib.rochester.edu/camelot/text/preiddeu-annwn. Jarman sintetiza muy bien el principal rasgo de Arturo al afirmar que "In this poem Arthur has severed all connections with the historical or semi-historical background sketched for him in some of the sources examined above and become the leader of a fantastic band of heroes possessing magical and superhuman powers" ("The Delineation of Arthur", p. 9). Respecto de los poemas artúricos galeses en general véase también JACKSON, Kenneth - "Arthur in Early Welsh Verse". in LOOMIS, Roger (ed.) - Arthurian Literature in the Middle Ages. Oxford: Clarendon Press, 1959, pp. 12-19; un buen resumen y textos traducidos en BOLLARD, John - "Arthur in Early Welsh Tradition". in LACY, Norris; WILHELM, James (ed.) - The Romance of Arthur: An Anthology of Medieval Texts in Translation. New York: Routledge, 2013, pp. 927. Todos estos poemas, si bien de datación problemática y conservados en manuscritos de los siglos XIII y XIV, fueron probablemente compuestos entre el 800 y el 1100.

${ }^{8}$ Respecto de las tríadas pertenecientes a la "versión antigua", datada hacia mediados del siglo XIII, que mencionan a Arturo véase TRIOEDD YNYS PRYDEIN. The Triads of the Island of Britain. Ed. e trad. Rachel Bromwich. $3^{\text {ra }}$ ed. Cardiff: University of Wales Press, 2006, y sobre el desarrollo de la figura de este personaje las pp. 280-283.

${ }^{9}$ EDEL, Doris - "The Arthur of Culhwch and Olwen as a figure of epic-heroic tradition". Reading Medieval Studies 9 (1983), pp. 3-15, p. 9.

${ }^{10}$ RODWAY, Simon - "The Date and Authorship of Culhwch ac Olwen: A Reassessment". Cambrian Medieval Celtic Studies 49 (2005), pp. 21-44. El texto se conserva en dos manuscritos, a saber: Peniarth ms. 4, conocido como Libro Blanco de Rhydderch, de c. 1350, y Bodleian Library, Jesus College 111 o Libro Rojo de Hergest, de c. 1382-1425. La edición estándar del texto es CULHWCH AC OLWEN. Ed. Rachel Bromwich; D. Simon Evans. $3^{\text {ra }}$ ed. Cardiff: University of Wales Press, 2012. Todas las citas se tomarán de esta edición, con indicación al número de línea. Los nombres en galés se han actualizado a la
} 
texto cincuenta años más tarde que la visión tradicional ${ }^{11}$, lo vuelve posterior a la Historia Regum Brittaniae de Godofredo de Monmouth (HRB) que, como es bien sabido, constituye un hito en la historia literaria artúrica ${ }^{12}$. Como se verá, independientemente de la dirección de la influencia de uno sobre otro - a propósito de la cual Rodway no ha encontrado ninguna evidencia concluyente respecto del conocimiento de la $H R B$ por el compositor de Culhwch, pero otros autores, como Roberts, postulan que Godofredo estaba familiarizado con el relato $-{ }^{13}$, el cuento galés expresa un punto de inflexión en el tratamiento de la materia artúrica del mismo modo que lo hace la $H R B$ cuyo autor, seguramente, conocía versiones previas o motivos e historias de las tradiciones vernáculas artúricas.

\section{Culhwch ac Olwen: características narrativas}

La historia de Culhwch, primo de Arturo, se enmarca dentro del motivo tradicional del héroe que obtiene la mano de la hija del gigante tras unas serie de pruebas (tipo 795) y combina numerosos temas provenientes de los cuentos tradicionales, como los seis que recorren el mundo o los ayudantes mágicos, los animales más antiguos, los animales agradecidos, entre otros ${ }^{14}$, con distintas tradiciones legendarias y literarias que circulaban en Gales respecto de Arturo, sus guerreros y su corte, en un tono por momentos jocoso y desvergonzado ${ }^{15}$. Al respecto, Edel propone lo siguiente:

\footnotetext{
ortografía moderna por ser estas versiones las de mayor circulación en la bibliografía. Por otro lado, las traducciones al castellano son de autoría propia.

${ }^{11}$ Por ejemplo, FOSTER, Idris Llewelyn - "Culhwch ac Olwen". in BOWEN, Geraint - Y Traddodiad Rhyddiaith yn yr Oesau Canol. Llandysul: Gomer, 1974, pp. 64-81.

${ }^{12} \mathrm{La} H R B$ fue publicada por Godofredo c. 1136 / 1138. Véase MONMOUTH, Geoffrey of - "De gestis Britonum". in The History of the Kings of Britain: An Edition and Translation of the "De gestis Britonum". Ed. Michael Reeve. Trad. Neil Wright. Woodbridge and New York: Boydell, 2007.

${ }^{13}$ RODWAY, Simon - "The Date and Authorship", pp. 38-43; ROBERTS, Brynley - "Culhwch ac Olwen, the triads, saints' lives". in BROMWICH, Rachel; JARMAN, A. O. H.; ROBERTS, Brynley The Arthur of the Welsh, pp. 73-95.

${ }^{14}$ Kenneth Jackson ha estudiado detenidamente los motivos internacionales de Culhwch ac Olwen y de la literatura galesa medieval en general en "The International Popular Tale in Early Welsh: 1". In The International Popular Tale and Early Welsh Tradition. Cardiff: University of Wales Press, 1961, pp. 6799. Thomas Jones ha examinado especialmente la historia de los animales más viejos y su desarrollo independiente en Gales antes de Culhwch ac Olwen en "Pethau nas cyhoeddwyd". Journal of the National Library of Wales VII.1 (1951), pp. 62-66. Véase también la introducción de Bromwich y Evans a la edición del texto, esp. pp. xxxiii-xxxix. Por su parte, Radner ha subrayado la parodia del autor en la utilización de dichos motivos folclóricos y la ironía que se obtiene del juego con las formas y motivos tradicionales. Véase RADNER, Joan - "Interpreting Irony in Medieval Celtic Narrative: The Case of Culhwch ac Olwen". Cambrian Medieval Celtic Studies 16 (1988), pp. 41-59.

${ }^{15}$ Respecto del humor como elemento esencial del relato véase STURZER, Ned - "The Purpose of Culhwch and Olwen". Studia Celtica 39 (2005), pp. 145-167.
} 
Culhwch ac Olwen consists of a series of originally independent Arthurian adventures, the majority of which stem from native epic-heroic tradition. This Arthurian material, with some later accretions, is brought together within the framework of the story of Olwen's wooing by Culhwch - this framework being formed by a combination of the stepmother-theme with the theme of the quest for the bride ${ }^{16}$.

El texto también se destaca por su carácter marcadamente dialógico, formulaico y visual, y es considerado, en este sentido, el más performativo de los cuentos de Mabinogion, la colección de once relatos galeses medievales ${ }^{17}$. La vocalidad del relato se complementa, sin embargo, con una retórica composicional muy artificiosa que puede observarse en la reelaboración de los motivos tradicionales que integran el texto y en los recursos literarios empleados por el narrador ${ }^{18}$. En esta misma línea, la gran cantidad de referencias y alusiones literarias, si bien muchas de ellas son inventadas, remiten a un saber poético con el que el narrador pretende entretener y sorprender a su público y demostrar sus habilidades literarias. El relato sorprende por su variedad de estilos, por momentos deteniendo la historia por completo, como en la larga conversación entre el gigante y el héroe Culhwch, pero generalmente siguiendo un ritmo rápido de acción tras acción.

El relato comienza con el nacimiento y crecimiento de Culhwch, quien recibe este nombre, "chiquero", debido a que su madre, aterrada por los cerdos, da a luz al ver a un porquerizo guardar los animales. No obstante, es de "noble linaje" (bonhedic, 1. 11) ya que es hijo de Cilydd, hijo del príncipe Celyddon Wledic y "primo hermano" (keuynderw, 1. 12) de Arturo. Su madre muere prematuramente tras una enfermedad y su padre, asesorado por sus consejeros, decide desposar a la mujer de otro rey, para lo cual, nos dice el texto, "Mataron al rey, se llevaron a su mujer y a su única hija y tomaron posesión de las tierras del rey" (“A llad y brenhin, a dwyn y wreic atref ganthu a orugant ac un uerch a oed idi gyd a hi. A gwereskyn tir y brenhin a wnaethant", 11. 3133). Este modo de comportamiento configura un código que reaparecerá en sucesivos acontecimientos. La nueva reina desea casar a Culhwch con su propia hija, pero este la

\footnotetext{
${ }^{16}$ EDEL, Doris - "The Arthur of Culhwch and Olwen", p. 7.

${ }^{17}$ DAVIES, Sioned - "Performing Culhwch ac Olwen". in LLOYD-MORGAN, Ceridwen (ed.) Arthurian Literature XXI. Cambridge: Brewer, 2004, pp. 29-51.

${ }^{18}$ ROBERTS, Brynley - "Tales and Romances". in JARMAN, A.O.H.; HUGUES, Gwilym R. - A Guide to Welsh Literature, vol. 1. Swansea: Cristopher Davies, 1976, pp. 203-243, y "Culhwch ac Olwen, the triads, saints' lives".
}

Medievalista online № 22 | Julho - Dezembro 2017 ( ) IEM - Instituto de Estudos Medievais 8 www2.fcsh.unl.pt/iem/medievalista 
rechaza. La madrastra, furiosa, lo maldice: "Juro un destino sobre ti: tu costado no se encontrará con una mujer hasta que conquistes a Olwen, hija de Ysbaddaden Bencawr [jefe de los gigantes]" ("Tyghaf tyghet it na latho dy ystlys vrth wreic hyt pan geffych Olwen merch Yspadaden Penkawr", 11. 50-51). Al oír el nombre de Olwen, "El muchacho enrojeció y el amor por la joven penetró en todos sus miembros a pesar de que nunca la había visto" ("Lliuaw a oruc y mab, a mynet a oruc serch y uorwyn ym pob aelawt itaw kyn nys rywelhei eiroet”, 11. 52-53). Frente a esta situación, su padre le aconseja buscar ayuda en la corte de su primo Arturo. A partir de este momento, la narrativa, que se perfilaba como historia de la biografía heroica de Culhwch, queda subsumida en el mundo artúrico y la escena principal es ocupada por Arturo y sus hombres. La segunda parte del relato comprende la búsqueda de Olwen, la llegada a la corte del gigante Ysbaddaden y la enumeración de una larga lista de tareas que el héroe debe llevar a cabo exitosamente si desea conseguir la mano de la joven; se narran a continuación una serie de aventuras protagonizadas por Arturo y sus hombres en las que Culhwch recibe un papel muy menor, hasta reaparecer en su final feliz.

\section{Arturo y la corte artúrica}

La escena de la llegada de Culhwch a la corte de Arturo, ubicada en Celli Wig (literalmente, "arboleda del bosque") en Cornualles ${ }^{19}$, y el diálogo que sigue entre el héroe y el "cuidador de la entrada" (motivo común que se repite en esta y en otras fuentes artúricas galesas, como en $\mathrm{Pa} g w r$ ?) nos transmiten algunas de sus principales características: para empezar, el acceso es custodiado por Glewlwyd Gafaelfawr, "el de Gran Puño", quien cumple la función de porthawr o "guardia de la entrada" también en otros textos galeses. Asimismo, está regulada por una serie de costumbres, "leyes de la corte de Arturo" (cyfreitheu llys Arthur, 1. 112) que sostienen los valores deseables, entre los que se encuentra la hospitalidad, fundamentalmente. El paso, sin embargo, es denegado: "El cuchillo está en la comida, la bebida en el cuerno y una multitud en la sala de Arturo" (“Kyllell a edyw ymwyt, a llynn ymual, ac amsathyr y neuad Arthur”, 1. 90, énfasis añadido), afirma Glewlwyd. A partir de este momento, solo puede ingresar el "hijo de un rey legítimo" ("mab brenhin gvlat teithiawc", 11. 90-91), o un artista, gerdawr, que ofrezca su arte, gerd. Este término generalmente denota al arte poético,

\footnotetext{
${ }^{19}$ Nótese que la corte está ubicada en la ciudad de Caerleon en la HRB y en los romans continentales.
} 
aunque en este relato son otros los oficios que prometen los personajes. No obstante, se brinda hospitalidad en la hospedería para extranjeros a todos aquellos que no cumplen con los requisitos previos:

Tendrás comida para tu perro y para tu caballo, y para ti chuletas calientes condimentadas con pimienta, vino rebosante y canciones placenteras. Te llevarán comida para cincuenta hombres en la casa de huéspedes. [...] No estarás peor allí que Arturo en su corte. Tendrás mujer con la cual dormir y canciones placenteras.

(Llith y'th gwn ac yd y'th uarch, a golwython poeth pebreit i titheu, a gwin goryscalawc, a didan gerdeu ragot. Bwyt degwyr a deugeint a daw attat y'r yspytty [...] Ny byd gwaeth it yno nocet y Arthur yn y llyd. Gwreic y gyscu gennyt, a didan gerdeu rac dy deulin, 11. 92-94, 96-98).

El nulo reconocimiento de Culhwch como hijo de un rey legítimo lo lleva a amenazar a la corte y a su guardia con aquello que resulta ser más significativo para la sociedad del relato: la reputación y el honor ("le llevaré deshonora a tu señor y un mal nombre a ti", "mi a dygaf anglot y’th arglwyd a drygeir y titheu", 1l. 103-104), así como también la fertilidad y prosperidad de la tierra (Culhwch gritará, y el grito se escuchará desde Cornualles hasta Irlanda y las mujeres perderán su embarazo). Glewlwyd busca entonces a Arturo, quien le solicita las "noticias de la entrada" (1. 115). Comienza así una enumeración de proezas (o micro-historias quizás independientes de hazañas militares y peleas contra criaturas sobrenaturales, del tipo "Yo estuve ahí en... cuando...") que funciona como comparación para subrayar las cualidades y el estatus de Culhwch (en un procedimiento que nuevamente nos recuerda a $\mathrm{Pa} g w r$ ?). Sin embargo, Cai, uno de los principales guerreros de Arturo, se pronuncia en contra de admitir al joven y contrariar las leyes de la corte, pese al noble retrato pintado por Glewlwyd. Es Arturo quien reprende a Cai e impulsa un nuevo comportamiento al enunciar, en un significativo parlamento, las vías hacia el prestigio y la cortesía, dejando entrever valores complementarios a aquellos asociados a la hazaña militar: "Somos nobles mientras se nos busque. Cuantos más regalos otorguemos, mayor será nuestra nobleza, nuestra fama y nuestro honor" ("Ydym wyrda hyt tra yn dygyrcher. Yd ytuo mwyhaf y kyuarws a rothom, mwyuwy uyd yn gwrdaaeth ninheu ac ancret ac anhetmic", 11. 136$138)^{20}$. Se observa aquí un germen del posterior desarrollo cortés de Arturo y su corte:

\footnotetext{
${ }^{20}$ Nótese que esta es la primera instancia del término gwrdaaeth, "aristocracia, nobleza, excelencia"
} $(G P C)$.

Medievalista online № 22 | Julho - Dezembro 2017 ( IEM - Instituto de Estudos Medievais 10 www2.fcsh.unl.pt/iem/medievalista 
el enaltecimiento de los personajes a partir de la ayuda a los demás se constituye en un valor deseable, junto con otras virtudes más allá de la fama. De esta manera, durante todo el relato, este aspecto protocortés coexistirá con la configuración en clave heroica de la figura de Arturo. La superposición de valores heroicos y corteses también se observa en el modo de referirse al espacio donde se desarrolla la vida de Arturo y sus guerreros: simultáneamente como neuad, "sala", y llys, "corte".

Culhwch, a continuación y luego de dirigirse a Arturo mediante una fórmula que examinaremos en la sección siguiente, saluda al resto de la corte respetando (y haciendo referencia a) la jerarquía que gobierna en ella: los de arriba y los de abajo, "nobles" (deon), "hueste" (niuer), y "conductores de huestes" (catbritogyon, 1. 144). De este modo remite, asimismo, a la disposición espacial durante las comidas: la ubicación de los guerreros en relación con el señor es sumamente importante en los relatos galeses ${ }^{21}$. De hecho, Arturo le ofrece el asiento entre dos de sus guerreros y afirma que tendrá "agradable canción y los privilegios de un edling" o "heredero natural" (11. 148-150). Se subraya, nuevamente, la generosidad de Arturo gracias a la distribución de dones entre huéspedes y gentes de lejos, y la extensión de su fama hasta las cuatro esquinas del mundo.

Acto seguido, Culhwch demanda un cyfarws o regalo, a costa del deshonor de Arturo (nuevamente observamos la relevancia del honor o la falta de él, que caracteriza gran parte de la literatura heroica). El otorgamiento del regalo implica el reconocimiento de Culhwch y su integración a la familia artúrica a través del corte y peinado de sus cabellos. Su solicitud, que no es otra que conseguir a Olwen, es invocada en nombre de los guerreros de Arturo aparentemente presentes. Sigue entonces una inmensa lista de

\footnotetext{
${ }^{21}$ Las leyes galesas establecen claramente dónde se sienta cada funcionario de la corte, es decir, cada uno de los hombres que desempeñaban cargos para el rey, como el sacerdote, el cazador, etc. (JENKINS, Dafydd - The Law of Hywel Dda. Llandysul: Gomer, 1986, pp. 7-8). En la corte (llys), el fuego del medio divide el espacio en una sección superior y otra inferior. En la primera, llamada uchkoryf, el rey se sienta cerca del fuego, a su lado el senescal, luego el anfitrión de la región donde se encuentre, y a su lado el edling o "heredero natural". En el iskoryf (también llamado en este pasaje de las leyes neuad, "sala") tiene su silla el penteulu ("jefe de la mesnada") junto con los que quiera de su teulu ("mesnada"). Parecería que Arturo ubica a Culhwch aquí, con sus guerreros, pero le otorga beneficios de rango superior. Todas las citas están tomadas de la redacción Iorwerth del manuscrito Peniarth 32 (Y LlyfrTeg), folios 5 y 6 . in "PENIARTH 32". Rhyddiaith Gymraeg 1300-1425. Ed. Diana Luft; Thomas Peter Wynn; D. Mark [en línea]. Cardiff: Cardiff University, 2013. Disponible en: http://www.rhyddiaithganoloesol.caerdydd.ac.uk
} 
héroes de toda clase (225 incluyendo repeticiones y 20 doncellas) ${ }^{22}$, cuyo análisis detallado ya ha sido emprendido por otros investigadores y su tratamiento excede el propósito de este trabajo ${ }^{23}$. Baste decir que en ella se observa en todo su esplendor la exageración y demostración de conocimiento y pericia retórica por parte del compositor que caracterizan el relato: juegos de palabras, aliteración, personajes con habilidades irrisorias $^{24}$, tríadas y referencias a héroes de otros dominios como tres reyes de Francia (nótese Gwilenhin, probable referencia a Guillermo el Conquistador), varios héroes irlandeses como Cú Chulainn, Conchobar mac Nesa, etc., varios monstruos, gigantes y figuras mitológicas como Manawydan mab Llyr. Todos estos ejemplos también expresan la capacidad que tiene la órbita artúrica de atraer personajes de muchas otras latitudes, enfatizando la importancia del rey y de su corte ${ }^{25}$.

Hasta aquí, es posible observar el poder de atracción de la corte de Arturo y la importancia de conservar sus tradiciones y costumbres. Es una corte renombrada que atrae guerreros por su reputación, pero también por la generosidad y hospitalidad de su señor. La lista de guerreros invocada por Culhwch, como subraya Roberts, indica el creciente magnetismo y la potencia de la leyenda de Arturo dentro de las tradiciones narrativas galesas ${ }^{26}$.

Otras cortes representadas en el texto arrojan, por contraste, más luz sobre la artúrica. La segunda parte del relato se abre con el viaje que el grupo de aventureros realiza hasta llegar al castillo del gigante Ysbaddaden. En este se describe un paisaje característico de la materia artúrica: cruzan una vasta llanura al final de la cual hay un gran castillo fortificado, el más bello del mundo. No descansan en todo el día y sin embargo no están más cerca a la noche de que lo que lo estuvieron a la mañana. En la cima de una colina

\footnotetext{
${ }^{22}$ En la lista de doncellas se encuentran Gwenhwyfar reina de Bretaña y su hermana Gwenhwyfach.

${ }^{23}$ EDEL, Doris - "The Catalogues in Culhwch ac Olwen and Insultar Celtic Learning". Bulletin of the Board of Celtic Studies 30 (1983), pp. 253-267. Patrick Sims-Williams estudia todas las referencias irlandesas del relato, incluidos los nombres irlandeses de la lista, en "The Irish Elements in Culhwch and Olwen". in Irish Influence on Medieval Welsh Literature. Oxford: Oxford University Press, 2010, pp. 134-187. También se ha planteado la posibilidad de que la lista sea una introducción posterior a la composición del relato. Véase CULHWCH AC OLWEN, p. xliv.

${ }^{24}$ Unos pocos ejemplos para ilustrar este punto: Gwefl hijo de Gwastad, quien los días en que estaba triste, soltaba uno de sus labios y lo dejaba caer hasta su ombligo y al otro lo usaba de capucha; Uchdryd Farf Draws, que podía arrojar la tupida barba roja que tenía por las cincuenta vigas de la sala de Arturo.

${ }^{25}$ Resulta pertinente acotar al margen, por último, que el catálogo podría ser considerado en su aspecto metaliterario, esto es, como muestra e índice de una forma de narrar.

${ }^{26}$ ROBERTS, Brynley - "Culhwch ac Olwen, the triads, saints' lives", p. 79.
} 
hay un pastor con un mastín enorme, Custennin, que luego sabremos que es el esposo de la tía de Culhwch. Custennin no solo cuida el rebaño del gigante sino que además cumple la función de "guardia de la entrada" y controla el ingreso a la fortaleza. Además, les avisa que ningún pretendiente de Olwen ha salido con vida del castillo. Justamente, el carácter inusual de este "guardia-pastor", junto con el hecho de que deben atravesar nueve entradas custodiadas por nueve guardias y nueve mastines para luego ingresar directamente a la sala, marca una profunda diferencia respecto de la corte de Arturo. El recibimiento de Ysbaddaden en su corte no es, ciertamente, amigable, dado que el gigante sabe que solo vivirá hasta que su hija tome esposo. La serie de episodios de entrada a una corte se completa con la llegada al castillo de Gwrnach el Gigante (la primera aventura que emprende el grupo). Toda esta escena plantea paralelismos directos con dos momentos previos. Por un lado, el diálogo con el hombre moreno de la fortaleza de Gwrnach reproduce el encuentro anterior entre el grupo de guerreros de Arturo y Custennin. Este les informa que ni un solo huésped extranjero ha salido con vida de la fortaleza, remitiendo al carácter negativo de la corte y a la imposición de costumbres distorsionadas. Por otro lado y más significativo aquí, el intercambio de Gwrhyr Gwalstawd Ieithoedd con el guardia de la entrada es prácticamente idéntico al de Culhwch con Gwelwyd Gafaelfawr. No obstante, solo un hombre que ofrezca un arte puede ingresar una vez comenzada la comida, el gigante los recibe cortésmente y son Cai y sus hombres quienes lo engañan no solo para entrar a su sala - nótese que no se utiliza nunca el término llys (corte) sino neuad (sala) -, sino también para robarle la espada, matarlo con ella y así saquear la fortaleza y llevarse sus riquezas y sus joyas. La situación, no exenta de cierto humor ${ }^{27}$, manifiesta la irreverencia del código de comportamiento de los guerreros artúricos y remite, nuevamente, a un determinado tipo de sociedad, como veremos en las conclusiones.

Ahora bien, otro aspecto importante de la popularidad de la corte artúrica es el propio Arturo en sus múltiples facetas: como soberano de la isla, señor protocortés, héroe emprendedor de aventuras, cazador y ayudante.

\footnotetext{
${ }^{27}$ Cai se hace pasar por bruñidor de espadas para ser admitido a la sala de Gwrnach, quien le da su propia espada y le permite invitar a sus compañeros, lo que genera una serie de discusiones en la entrada. Recuérdese que el padre de Culhwch se comporta de manera similar para conseguir nueva esposa.
} 


\subsection{Arturo se lanza a la aventura: guerrero, cazador, poeta y pacificador}

La introducción de Arturo en la narrativa nos plantea un aspecto de su persona (y de su corte) que hemos denominado protocortés. Su aparición siguiente sucede cuando Culhwch, luego de irrumpir en la corte sin desmontar - marcando un claro contraste con el discurso cortés de Arturo y con la magnánima descripción realizada por Glewlwyd, hecho que genera cierta comicidad -, lo saluda como Penn Teyrned yr Ynys honn, "jefe de los príncipes de esta isla" (1l. 142-143), título que subraya su papel de rey de reyes y marca un contraste con la imagen de Arturo como jefe de una banda de guerreros de los poemas mencionados al inicio. A este carácter soberano del rey se suma inmediatamente otro: Arturo concede a Culhwch su regalo bajo ciertas condiciones, que manifiestan no solo su generosidad sino, principalmente, sus pertenencias más valiosas:

obtendrás el presente que nombren tu boca y tu lengua, tan lejos como seque el viento, moje la lluvia, gire el sol, se extienda el mar y haya tierra, a excepción de mi barco y mi capa, de Caledfwlch ["la que hace brecha en batalla"], mi espada; Rhongomyniad ["lanza empaladora"], mi lanza; Gwyneb Gwrthucher ["rostro al atardecer"], mi escudo; Carnwennan ["manguito blanco"], mi cuchillo, y Gwenhwyfar ["hada o hechicera blanca"], mi mujer (11. 156-162).

La lista de objetos artúricos se completa posteriormente con su barco Prydwen ("forma blanca”, 11. 938, 1041) y su yegua Lamrei (1. 1016), su mastín Cafall (“caballo”, 1. 1015) y su sala Ehangwen (“amplia y clara", 1. 264). Como se observa, se trata del equipo de un guerrero. Nótese que si bien Arturo no posee ninguna habilidad mágica por sí mismo, a diferencia de sus seguidores (aunque sí despliega fuerza sobrehumana), gran parte de los nombres de su regalia, incluida el de su esposa, contienen el elemento "blanco" (gwyn en masculino, gwen en femenino), cuyo sentido también cubre el de "puro" o "sagrado" y que se asocia con lo sobrenatural y el otro mundo ${ }^{28}$.

El Arturo de la segunda parte del relato, que narra la expedición en busca de Olwen y las aventuras posteriores, no es la figura estática característica de la tradición posterior (el llamado rex inutilis $)^{29}$, sino, muy por el contrario, un rey muy activo que deja sus

\footnotetext{
${ }^{28}$ FORD, Patrick K. - "On the Significance of some Arthurian Names in Welsh". Bulletin of the Board of Celtic Studies 30 (1983), pp. 268-273, p. 268.

${ }^{29}$ PETERS, Edward- The Shadow King. Rex inutilis in Medieval Law and Literature. New Haven y London: Yale University Press, 1970, pp. 170-209. Köhler utilizó la expresión roi fainéant (rey flojo o
} 
huellas por todo el paisaje de la isla. Es también quien designa a los seis ayudantes de Culhwch, cada uno con una cualidad maravillosa que aporta un saber especial al grupo de exploradores y guerreros: Cai el privilegiado, es el que tiene más poderes (puede aguantar la respiración bajo el agua durante nueve días, las heridas que inflige son incurables, es astuto, puede ser más alto que el árbol más alto y emana tanto calor que nada alrededor de él se moja y puede prender fuegos); Bedwyr es el más noble y mejor guerrero (es apuesto, temerario cuando está con Cai y puede vencer hasta a tres guerreros con una sola mano) ${ }^{30}$; Cynddylig Gyfarwydd, "el guía”; Gwrhyr Gwalstawd Ieithoedd, "interpretador de lenguas"; Gwalchmai hijo de Gwyar, el mejor jinete y sobrino de Arturo; y Menw hijo de Teirgwaedd el mago.

Cabe destacar, asimismo, que la aventura iniciada en medio de la cena no es individual sino colectiva, y concretiza el relato posible abierto por las leyes de la corte. La efectiva ejecución exitosa de las aventuras es un trabajo en equipo, en el que cada individuo aporta su saber o habilidad especial. Este carácter comunitario es sumamente importante como marca de contraste con la individualidad prototípica del caballero errante de la literatura artúrica posterior ${ }^{31}$.

Una vez en presencia del gigante Ysbaddaden, se inicia una secuencia que se repite durante tres días consecutivos, narrada a partir de elementos fijos y variables: Culhwch y sus compañeros demandan la entrega de Olwen, Ysbaddaden pide que le suban los párpados para poder ver a su futuro yerno y al final les lanza una jabalina envenenada, que es devuelta por dos de los ayudantes y finalmente por Culhwch mismo. Luego de esta confrontación, Ysbaddaden le impone una lista de treinta y nueve anoethau ${ }^{32}$, "maravillas", “tareas u objetos difíciles de conseguir", cuya enumeración está

perezoso) para referirse a Arturo como figura pasiva, de acuerdo con los propósitos ideológicos de Chrétien en relación con la realeza. Véase KÖHLER, Erich - "Le Rôle de la coutume dans les romans de Chrétien de Troyes". Romania 81 (1960), pp. 386-397. Remitimos a las conclusiones para una discusión más amplia relativa al contexto histórico vinculado con estos aspectos.

${ }^{30}$ Cai y Bedwyr son dos guerreros asociados con Arturo desde los primeros registros en lengua vernácula.

${ }^{31}$ Este mismo aspecto de "collectivism" ha sido propuesto por Fulton en relación con los relatos artúricos galeses Owein y Gereint. FULTON, Helen - "Individual and Society in Owein/Yvain and Gereint/Erec". in FALAKY NAGY, Joseph (ed.) - The Individual in Celtic Literatures. Dublin: Four Court Press, 2001, pp. $15-50$.

${ }^{32}$ Una tarea más está presupuesta en el desarrollo posterior de la acción: la consecución de los dos cachorros de la perra Rymhi, lo que incrementa a cuarenta los anoethau. Véase CULHWCH AC OLWEN, nota a la línea 701 (p. 134). 
enmarcada en la conversación que sostienen ambos personajes y que se inicia con la frase "Cuando yo consiga aquello que te pediré, tú conseguirás a mi hija" ("Pan gaffwyf inheu a nottwyf arnat ti, titheu a geffy uy merch", 11. 567-568) y culmina con "Busca esas cosas. Y cuando las consigas, obtendrás a mi hija” ("Keis hynny. A ffan gaffer hynny, vym merch inheu a geffy", 11. 757-758). Cada prueba es introducida a partir de las fórmulas introductorias "Aunque consigas eso, hay algo que no conseguirás" ("Kyt keffych hynny, yssit ny cheffych”, 1. 578 et passim), dice el gigante, a lo que Culhwch responde "Obtener eso es fácil para mí, aunque te parezca que no sea fácil" ("Hawd yw genhyf gaffel hynny kyt tybycckych ti na bo hawd", 11. 582-583 et passim). Todas estas tareas se pueden agrupar en dos grandes series: las preparaciones para el festejo nupcial y el acicalamiento del gigante para la boda, cuyo éxito depende del suceso central, la caza del jabalí salvaje Twrch Trwyth (“jabalí Trwyth”).

De las treinta y nueve tareas, solo diez son realizadas y narradas, es decir, se describen los distintos pasos para conseguir el objeto o sujeto en cuestión. Cada una tiene como marco introductorio un dispositivo de enunciación familiar a la leyenda artúrica: la salida de la corte y el posterior regreso y relato de la aventura. Arturo es el que propicia las expediciones en consejo con sus hombres mediante la fórmula introductoria “¿Cuál de esas maravillas es mejor buscar primero?" ("Pa beth yssyd iawnaf y geissaw gyntaf o'r annoetheu hynny?", 11. 826-7; cp. 11. 929-30, 985-6, 1205-6) y encabeza él mismo algunas de ellas. Nuevamente, se concretiza la experiencia de la aventura en conjunción con el relato de esta. Varios de estos episodios son tradicionales en su tema respecto de la materia artúrica galesa, como la liberación de prisioneros, el enfrentamiento contra brujas y gigantes, la obtención de objetos mágicos ${ }^{33}$. El rey convoca a los "guerreros de la isla de Britania” (“milwyr Ynys Prydein”, 11. 829-30; cp. 11. 922-3), a quienes el narrador se refiere alternativamente como "tropa" de Arturo (llu, 1. 941, luoed 11. 1096, 1139, 1197), "hueste” (niuer, 1. 1024), "soldados" (gynifywr, 1. 1057); Arturo los llama "mis hombres" ('m gwyr, 1. 1169). Resulta importante mencionar aquí que la propia teulu del rey, su familia o círculo más cercano de parientes, es decir, su mesnada, contribuye en la tarea más difícil, la caza del jabalí.

\footnotetext{
${ }^{33}$ ROBERTS, Brynley - "Culhwch ac Olwen, the triads, saints' lives", p. 78.
} 
Durante el relato de las distintas aventuras, aparecen diversas facetas del rey: como guerrero, cazador, poeta y pacificador. Como guerrero, de más está decir que es intrépido, fuerte y protector de sus hombres. De hecho, estos afirman que su dignidad es tal que no debe ser molestado para cosas triviales como descubrir el paradero de Mabon (a quien necesitan para cazar al jabalí) o combatir contra la bruja del norte: "Señor, vete a casa. No puedes venir con tu tropa a buscar cosas tan ínfimas como estas" (“Arglwyd, dos di adref. Ny elly di uynet a'th lu y geissaw peth mor uan a'r rei hynn", 11. 839-840), le dicen. Arturo delega explícitamente la misión (neges, 1. 842) en sus hombres para que la realicen en su lugar. Lidera en total siete episodios, que subrayan la bravura de Arturo y su poderío militar: el rescate de Eidoel, que se consigue de forma pacífica (y, de hecho, Arturo gana un vasallo más); la liberación de Mabon; los dos cachorros de la perra Rymhi; la persecución y muerte del jabalí Ysgithrwyn Pen Baedd; la caza del jabalí salvaje Twrch Twryth y sus descendientes; la expedición a Irlanda en busca del caldero de Diwrnach; el episodio de la sangre de la bruja del norte Gwiddon Orddu ${ }^{34}$. Con respecto a la anteúltima aventura, el tema del viaje con el fin de apropiarse de un caldero mágico aparece ya en el poema Preiddeu Annwn, como hemos visto. En el relato en prosa, Arturo y sus seguidores se embarcan en su barco Prydwen, llegan a Irlanda y, como Diwrnach se niega a entregar el objeto, matan a todos, saquean el lugar y se llevan el caldero lleno de tesoros. Nuevamente, el saqueo explicita un modo de proceder que dista de la actitud cortés.

El suceso central, la caza del jabalí salvaje Twrch Trwyth y sus descendientes, es un tema que también tratan varias fuentes galesas, entre ellas, la Historia Brittonum. Se trata de la tarea más difícil que deben enfrentar y en la que se destaca otra faceta del rey: la de cazador. Arturo reúne a todos los guerreros, perros y caballos de fama de sus dominios: la isla de Bretaña, sus tres islas adyacentes, Francia, Armórica, Normandía y el País del Verano (la península suroeste). El jabalí y sus descendientes escapan haciendo destrozos por Irlanda, Gales y Cornualles, y son básicamente imparables. Cuando Arturo llega a Irlanda, al contrario de lo que ocurre en la expedición anterior, los santos del país se entrevistan con él y promete no dañar a la población, de la que

\footnotetext{
${ }^{34}$ A esta lista habría que agregar aquellos objetos cuya obtención no es narrada más que al pasar, a saber: Myngddwn, el corcel de Gweddw; la correa de Cors Cant Ewin; los dos perros de Glythfyr Ledewig; Gwrgi Seferi y Cyledyr Wyllt.
} 
recibe ayuda. Actúa, de este modo, como protector de un pueblo: en vez de saquear, recibe tributo. Por otro lado, los jabalíes van arrasando todo lo que encuentran a su paso; Arturo combate contra ellos durante nueve días y solo consigue matar a uno de los cerditos (11. 1072-1073). Finalmente, luego de grandes desplazamientos e innumerables pérdidas, el rey, junto con los pocos que quedan, termina expulsándolos de la isla, y su destino es desconocido. En esta línea, Pastoureau ha finamente explicado la caza del jabalí como actividad guerrera, peligrosa y salvaje, que concluye en un enfrentamiento cuerpo a cuerpo entre bestia y cazador. Como afirma el autor, "Être vainqueur d'un sanglier est toujours un exploit" ${ }^{35}$.

Justamente, lo que Pastoureau reconoce encuentra un nivel más profundo de significación dentro de la tradición galesa, cuya literatura vuelve una y otra vez sobre la práctica de la caza y los animales salvajes que ayudan o enfrentan a distintos personajes - recurrencia que proviene de la centralidad de estos temas en la cultura céltica antigua. Entre ellos, el jabalí ocupa un lugar de gran relevancia simbólica, en especial su caza: como pasatiempo deportivo de la elite aristocrática, funcionaba como simulación y práctica para el combate. De hecho, el jabalí era un símbolo de guerra. Su carácter ritualista queda subrayado por el escaso registro arqueológico doméstico que atestigüe la caza como sustento nutricional frente a la abundancia de iconografía (estatuillas y relieves en piedra o metal) y fuentes escritas que lo representan. Estaba fuertemente vinculado con lo sobrenatural e incluso asociado con la divinidad. Por esta razón, existía una actitud ambivalente respecto de la caza del jabalí: simbolizaba al mismo tiempo la muerte (la destrucción de parte de la naturaleza) y la vida (la supervivencia y reproducción $)^{36}$. Resulta particularmente productivo notar en este contexto que Pastoureau plantea como una de las causas de la desvalorización del jabalí a favor del ciervo la simbología infernal asociada con este en los escritos de numerosos autores cristianos, que lo convierten en una bestia impura, enemiga del bien, imagen del hombre pecador y rebelado contra Dios, de ferocidad diabólica. A propósito de ello, Twrch Trwyth es un rey que fue convertido en jabalí por sus pecados y presenta claramente

\footnotetext{
${ }^{35}$ PASTOUREAU, Michel - "Chasser le sanglier. Du gibier royale à la bête impure: histoire d'une dévalorisation". in Une histoire symbolique du Moyen Âge occidental. Paris: Seuil, 2004, pp. 73-88, p. 74.

${ }^{36}$ En todo esto seguimos a GREEN, Miranda - Animals in Celtic Life and Myth. London y New York: Routledge, 2002.
} 
connotaciones negativas como "jabalí de la destrucción”. El enfrentamiento de Arturo con dos de estas criaturas (el anterior había sido Ysgithrwyn Pen Baedd) no solo encarna la lucha del bien contra el mal sino que además constituye su reafirmación como rey guerrero y su legitimación como soberano dentro del tipo de sociedad que se configura en el relato, como veremos en las conclusiones.

La bravura de Arturo y su poderío militar reaparecen en el episodio de la sangre de la bruja del norte, quien había logrado golpear a los hombres de Arturo, desarmarlos y echarlos de la cueva chillando (1. 1217), escena cómica que viene inmediatamente después del episodio central de la caza de Twrch Trwyth y genera un clima completamente antiheroico. Es finalmente Arturo quien, con su cuchillo Carnwennan, vence a la bruja Gwiddon Orddu partiéndola a la mitad, hazaña claramente sobrehumana.

Como se desprende de lo anterior, el papel heroico de Culhwch se desdibuja por completo durante el relato. En efecto, en la escena final, Ysbaddaden es quien afirma que debe agradecer a Arturo por haber conquistado los objetos maravilloso y, de este modo, a Olwen por él: "Y no necesitas agradecerme a mí por eso, sino a Arturo, quien lo hizo por ti” (“Ac nyt reit itt diolwch y mi hynny, namyn diolwch y Arthur y gwr a'e peris itt”, 11. 1236-1237).

La tercera dimensión de Arturo, como poeta, se manifiesta cuando canta un englyn, una composición en verso estrófica de tres líneas, burlándose de Cai. Este personaje, al igual que el rey, aparece en un momento de transición entre el Cai heroico y el (des)cortés de la leyenda posterior: es el que más facultades maravillosas posee pero ya comienza a perfilarse su carácter fácilmente irascible y maledicente; en ambos casos, no obstante, representa la discordia dentro de la corte ${ }^{37}$. En este episodio se enemista con Arturo y decide no hablarle más. Es preciso recordar, sin embargo, que en la lista de guerreros que invoca Culhwch se menciona a Gwyddog hijo de Menestyr y se afirma que "mató a Cai y Arturo lo mató a él y a sus hermanos para vengar a Cai” (“[a] ladawd Kei, ac Arthur a'y lladawd ynteu a'r urodyr yn dial Kei”, 11. 283-284). Aquí se expresa

${ }^{37}$ Como afirma BOUTET, Dominique - "Carrefours idéologiques de la royauté arthurienne". Cahiers de civilisation médiévale 28 (1985), pp. 3-17, pp. 11-12, donde el autor rastrea su función indoeuropea.

Medievalista online $\mathrm{N}^{\circ} 22$ | Julho - Dezembro 2017 ( ) IEM - Instituto de Estudos Medievais 19 www2.fcsh.unl.pt/iem/medievalista 
claramente el fuerte vínculo que une al señor con sus hombres. Por último, nótese que Arturo aparece como uno de los "Tres Poetas Frívolos (o Amateurs) de la Isla de Bretaña" y en varias composiciones le son atribuidos poemas satíricos ${ }^{38}$. Finalmente, el rey aparece como pacificador y mediador en el conflicto entre Gwyn hijo de Nudd y Gwythyr hijo de Greidol a raíz del rapto de la mujer de este último. De esta manera consigue que ambos lo ayuden en una aventura posterior.

Tres indicios de la imagen de Arturo, de su corte y de sus guerreros que se construye en este relato se pueden localizar en la hagiografía latina, como advierte Roberts ${ }^{39}$. En primer lugar, el título "jefe de los príncipes de esta isla" con el que Culhwch saluda a Arturo es similar a aquellos utilizados en las vidas de santos galeses, tales como "rex totius majoris Brittanie, rex illustrissimus Britannie, rex universale Brittanie" 40 . En segundo lugar, en la Vita Iltuti, el santo decide visitar la corte artúrica luego de escuchar "la magnificencia de su primo, el rey Arturo" ("Arthurii regis sui consobrini magnificentiam") ${ }^{41}$, a cuya corte se encamina. Al llegar, ve "una gran cantidad de soldados, que también son recibidos con honor en ese lugar y son recompensados en relación con su deseo militar" ("maximam militum habundantiam, ibidem quoque receptus honorifice, et munificatus ad desiderium militare") ${ }^{42}$, satisfacción que él recibe del mismo modo. Siguiendo a Roberts, parece ciertamente que la visita de un héroe a la corte artúrica se estaba convirtiendo en una característica estereotipada ${ }^{43}$. Asimismo, la idea de corte de gran reputación, que atrae guerreros, está presente en estos ejemplos, así como también la magnanimidad de Arturo. Por último, en la Vita Cadoci, Cai y Bedwyr disuaden a Arturo de la abducción de la joven princesa Gwladus (quien, a su vez, había sido raptada por Gwynlliog, con quien se casará y concebirá al santo), al recordarle que su deber es ayudar a aquellos que lo necesitan: "pues nosotros estamos acostumbrados a socorrer a los indefensos y a los que están en apuros" (“nos enim soliti

\footnotetext{
38 TRIOEDD YNYS PRYDEIN, pp. 22-24.

${ }^{39}$ ROBERTS, Brynley - “Culhwch ac Olwen, the triads, saints' lives”. Recuérdese que se trata de textos del siglo XII, algunos, como la Vita Cadoci, anteriores a la $H R B$.

${ }^{40}$ ROBERTS, Brynley - "Culhwch ac Olwen, the triads, saints' lives", p. 82.

${ }^{41}$ VITAE SANCTORUM Britanniae et genealogiae. Ed. Arthur Wade-Evans. Cardiff: University of Wales Press, 1944, p. 196. Las traducciones al castellano son propias.

${ }^{42}$ VITAE SANCTORUM Britanniae et genealogiae, p. 196.

${ }^{43}$ ROBERTS, Brynley - "Culhwch ac Olwen, the triads, saints' lives", p. 82.
} 
sumus inopes anxiosque iuuare" ${ }^{44}$. Este parlamento plantea serias similitudes con el discurso de Arturo antes de la llegada de Culhwch.

\section{Conclusiones}

Todo lo anterior subraya cuán compleja e incluso contradictoria es la figura de Arturo en Culhwch ac Olwen (y, podríamos agregar, en las tradiciones galesas en general). En este relato se construye una figura de Arturo y de su corte que superpone elementos heroicos, tales como el acento en la acción militar, el perfil guerrero del rey, valores como lealtad al señor, búsqueda de fama, valor marcial, generosidad, el saqueo, el espacio de la sala, con elementos que podríamos llamar protocorteses. Ilustran este último rasgo el ambiente de la corte que atrae a los guerreros por su reputación y la posibilidad de la aventura, la imagen de Arturo como soberano y rey de reyes, su autoridad y poderío sobre toda la isla y tierras extranjeras, su faceta como pacificador y como protector de las costumbres y leyes de su corte, la idea emergente de un elenco más o menos estable de guerreros alojados en su corte ${ }^{45}$. De este modo, la figura de Arturo se encuentra en un punto de transición entre el jefe de una banda de guerreros o líder heroico del pasado galés y el emperador de la $H R B^{46}$. Ahora bien, respecto de la datación de Culhwch ac Olwen y su relación con la $H R B$, es posible observar múltiples continuidades entre una obra y otra. Como afirma Padel, "It is clear that the portrayal of Arthur in CULHWCH, and also the hunting of the TWRCH TRWYTH, go back centuries earlier than Geoffrey's HISTORY, so the dating of CULHWCH, whether earlier than the HISTORY or not, does not fundamentally affect our view of the developing figure of Arthur" (mayúsculas en el original) ${ }^{47}$. Ciertamente, los años comprendidos entre 1100-1150 constituyen un periodo de cambio en la literatura artúrica.

\footnotetext{
${ }^{44}$ VITAE SANCTORUM Britanniae et genealogiae, p. 26.

${ }^{45}$ Esta idea de corte de Arturo está también presente en la redacción más antigua de las Tríadas de la Isla de Bretaña conservada en el ms. Peniarth 16. En la tríada 9 se enumeran los "Tres Capitanes de la Corte de Arturo: Gobrwy hijo de Echel Fordwytwll, Cadrieith hijo de Porthawr Gadw y Fleudur Fflam" (TRIOEDD YNYS PRYDEIN, p. 16). Tanto Gobrwy como Fleudur aparecen mencionados en la lista de nombres invocados por Culhwch.

${ }^{46}$ Texto que, como sabemos, se nutre de fuentes galesas y de modelos clásicos para narrar la primera biografía de Arturo. Foster señala también algunos elementos de Culhwch ac Olwen presentes en textos franceses e ingleses en FOSTER, Idris Llewelyn - "Culhwch ac Olwen and Rhonabwy's Dream". in LOOMIS, Roger (ed.), Arthurian Literature in the Middle Ages, pp. 31-43, esp. p. 39.

${ }^{47}$ PADEL, Oliver - Arthur in Medieval Welsh Literature, p. 76.
} 
Por todo esto, Culhwch ac Olwen ocupa un puesto destacado en la historia literaria artúrica. No carece de relevancia subrayar que se trata de la primera obra en prosa en una lengua vernácula en la que se nos presenta una idea de corte artúrica más o menos coherente. La corte aparece ya como dispositivo literario que enmarca las aventuras que se viven grupalmente y que también se relatan. La autoridad de Arturo está in crescendo aunque no legitima un código caballeresco, sino que fluctúa con una conducta más cercana a la heroica. El rey generoso y afamado propicia aventuras que permitirán luego el saqueo y el acrecentamiento de riquezas, así como también de estatus. Estos rasgos de Arturo, sus actitudes y comportamientos, así como también su caracterización como activo "jefe de los príncipes de esta isla", destacan que la forma en que el texto recoge y combina temas y modelos narrativos y configura, de este modo, un retrato de Arturo, de su corte y sus guerreros, depende, en gran medida, de las condiciones específicas del contexto de producción, difusión y recepción del relato. En este sentido, la historia literaria artúrica también transmite diferentes modos de organización social y concepciones acerca del poder real: el contraste entre el Arturo de Culhwch ac Olwen y el ulterior rey continental obedece a modelos regios originados en sociedades muy distintas, y expresa lógicas de funcionamiento cultural y socio-económico de diverso orden. En el texto galés, Arturo es un rey guerrero que gobierna sobre un mundo de maravillas y su poder y legitimidad reales se sostienen sobre la base de sus formidables hazañas y su familia y mesnada, compuesta por luchadores que poseen habilidades mágicas y lo reconocen como líder. Su capacidad para vencer enemigos y detener invasores prueba su liderazgo y lo cualifican como rey supremo de las Islas Británicas, situándose la acción en un pasado legendario de soberanía britana. En efecto, Arturo personifica la soberanía del gobierno britano sobre un reino insular unificado usurpado primero por los anglosajones y luego por los normandos ${ }^{48}$. El núcleo de la sociedad representada, cuyas preocupaciones y esperanzas atraviesan todo el texto, es la aristocracia guerrera sustentada sobre la mesnada y dueña de la tierra, cuya explotación constituía, junto con el saqueo, las principales actividades económicas. La caza como estilo de vida forma también parte de este modo social. Es decir, se trata, hasta cierto punto, de una sociedad de carácter tribal o heroico, como era la galesa hasta el siglo XII;

\footnotetext{
${ }^{48}$ Se tratan estos de temas elaborados por la historiografía tradicional galesa: la unidad geográfica y política de la isla (una corona, un rey), y la pérdida de soberanía y unidad. Véase ROBERTS, Brynley "Geoffrey of Monmouth and Welsh Historical Tradition". Nottingham Medieval Studies 20 (1976), pp. 29-40.
} 
altamente volátil y competitiva. ${ }^{49}$ Los vínculos familiares y personales entre el señor y sus hombres, el honor y el estatus, son clave para entender la estructura social que sostiene la narrativa y motiva la acción, así como también la inquietud por el control territorial y la descendencia.

Ahora bien, el siglo XII es una época de cambios. Como señala el prestigioso historiador galés R. R. Davies, a partir de este momento la política basada en una elite heroica dio progresivamente paso a la consolidación de un poder real centralizado, proceso análogo, aunque probablemente más tardío, al del resto de Europa. Los reyes siguieron siendo líderes guerreros pero se afianzaron sus poderes de gobierno y justicia: la consolidación y centralización del poder real se concretizó en la definición y regularización de formas de autoridad y explotación. Estos cambios se produjeron a la par de una modificación de la mentalidad de los grupos dominantes. ${ }^{50}$ En este sentido, Culhwch ac Olwen no solo reivindica un pasado legendario de unidad y soberanía sino que, además, podía encontrar una buena recepción dentro de la aristocracia galesa contemporánea en el modelo de realeza doble encarnado en Arturo.

Por último, resulta significativo notar que esta tensión entre un Arturo que hemos denominado heroico y uno cortés atraviesa los relatos artúricos galeses posteriores Chwedl Iarlles y Ffynnon (Owain), Ystoria Geraint fab Erbin e Historia Peredur fab Efrog, que narran historias paralelas a las de Yvain ou Le chevalier au lion, Erec et Enide y Perceval ou Le conte du graal, respectivamente, de Chrétien de Troyes. Cada uno merece ser estudiado individualmente en cuanto a su posible relación con una fuente francesa, pero baste decir aquí que, en el caso de Owain, la ambivalencia del carácter de Arturo es notable. Los investigadores tienden a estar de acuerdo en que el retrato de Arturo es más parecido al modelo continental emergente que al de las fuentes

\footnotetext{
49 Varios de estos puntos han sido desarrollados por FULTON, Helen - "Arthur and Merlin in Early Welsh Literature: Fantasy and Magic Naturalism". in FULTON, Helen (ed.) - A Companion to Arthurian Literature. Maldon, MA and Oxford: Wiley-Blackwell, 2009, pp. 84-101, p. 95; KNIGHT, Stephen Arthurian Literature and Society. Respecto del modo en que se presenta el poder real en las obras francesas véase BOUTET, Dominique - "Carrefours idéologiques de la royauté arthurienne", donde el autor rastrea cómo, por ejemplo, en el roman de Chrétien de Troyes Arturo representa un rey feudal, garante de un orden que lo supera, sustentado en una visión de mundo.

${ }^{50}$ DAVIES, Robert Rees - The Age of Conquest. Wales 1063-1415. Oxford: Oxford University Press, p. 157.
} 
galesas o latinas más antiguas ${ }^{51}$. Esto queda claro desde el inicio: en la escena de apertura, es llamado "emperador" (amherawdyr) dos veces. A diferencia de Culhwch ac Olwen, en Iarlles está ocioso en la corte, soñoliento y viejo. A pesar de la preeminencia de este último aspecto del rey, huellas de una imagen mixta de Arturo se manifiestan en tres ocasiones: cuando se prepara para combatir contra el Caballero del Pozo (Owain de incógnito), cuando Owain abandona su tierra y su esposa para hacer el circuito con él, y cuando Arturo lo designa como pennteulu, líder de la mesnada. En todas estas instancias, Arturo aparece como el jefe, el señor y la cabeza de la familia a la que pertenece Owain. Este retrato tensionado de Arturo es probablemente resultado de las representaciones anteriores del rey, como la que se nos presenta en Culhwch ac Olwen. Asimismo, como ha observado Owen, la atmósfera general configurada en el texto desde el inicio y mantenida en toda la narrativa es muy similar a la del roman francés. De este modo, presenta un carácter diferente al de la poesía cortesana contemporánea o, lo que es más, de las composiciones "nativas". El valor de la cortesía y de las costumbres sociales de la corte (llys y rhamantau), los torneos y los caballeros errantes son, según lo que indica la evidencia, introducciones producto de la influencia francesa ${ }^{52}$. Como se ha intentado argumentar, existe ya un germen de estas características en la obra estudiada aquí.

Con todo, Culhwch ac Olwen es un verdadero textus en el que confluyen diversos modelos narrativos: motivos provenientes del cuento tradicional, historias locales galesas, fuentes latinas, poesía artúrica, que el autor reelabora y combina en la creación de esta obra singular. De esta forma, sienta las bases del rey Arturo que, una vez popularizado por el roman courtois continental, llevará su fama, ciertamente, hasta las cuatro esquinas del mundo.

\footnotetext{
${ }^{51}$ ROBERTS, Brynley - "The Welsh Romance of the Lady of the Fountain (Owein)". in GROUT, P. et alii (ed.) - The Legend of Arthur in the Middle Ages, pp. 170-82.

52 OWEN, Morfydd - “'Arbennic milwr a blodeu marchogyon': Cymdeithas Peredur". in DAVIES, Sioned; THOMAS, Peter Wynn (ed.) - Canhwyll Marchogyon: Cyd-destunoli Peredur. Cardiff: University of Wales Press, 2000, pp. 91-112. El tema de la impronta francesa sobre Owain fue tratado in extenso en mi tesis doctoral. Véase CORDO RUSSO, Luciana - The Reception of Medieval French Narrative in Medieval Wales: The Case of Chwedyl Iarlles y Ffynnawn and Cân Rolant. Buenos Aires: Universidad de Buenos Aires, 2015. Tesis Doctoral.
} 


\section{Referências bibliográficas:}

\section{Fontes}

CULHWCH AC OLWEN. Ed. Rachel Bromwich; D. Simon Evans. $3^{\text {ra }}$ ed. Cardiff: University of Wales Press, 2012.

MONMOUTH, Geoffrey of - "De gestis Britonum". in The History of the Kings of Britain: An Edition and Translation of the "De gestis Britonum". Ed. Michael Reeve. Trad. Neil Wright. Woodbridge and New York: Boydell, 2007.

"PENIARTH 32". Rhyddiaith Gymraeg 1300-1425. Ed. Diana Luft; Thomas Peter Wynn; D. Mark [en línea]. Cardiff: Cardiff University, 2013. Disponible en: http://www.rhyddiaithganoloesol.caerdydd.ac.uk

TRIOEDD YNYS PRYDEIN. The Triads of the Island of Britain. Ed. e trad. Rachel Bromwich. $3^{\text {ra }}$ ed. Cardiff: University of Wales Press, 2006.

VITAE SANCTORUM Britanniae et genealogiae. Ed. Arthur Wade-Evans. Cardiff: University of Wales Press, 1944.

\section{Estudos}

AURELL, Martin - La légende du roi Arthur 550-1250. Paris: Perrin, 2008.

BOLLARD, John - "Arthur in Early Welsh Tradition”. in LACY, Norris; WILHELM, James (ed.) - The Romance of Arthur: An Anthology of Medieval Texts in Translation. New York: Routledge, 2013, pp. 9-27.

BOUTET, Dominique - "Carrefours idéologiques de la royauté arthurienne". Cahiers de civilisation médiévale 28 (1985), pp. 3-17.

BROMWICH, Rachel - “Concepts of Arthur”. Studia Celtica 10 (1975-1976), pp. 163181. 
- "Celtic Elements in Arthurian Romance: a General Survey". in GROUT, P. et alii (ed.) - The Legend of Arthur in the Middle Ages. Studies presented to A. H. Diverres. Woodbridge: Brewer, 1983, pp. 41-55.

BURGESS, Glyn; PRATT, Karen (ed.) - The Arthur of the French. The Arthurian Legend in Medieval French and Occitan Literature. Cardiff: University of Wales Press, 2006.

CHARLES-EDWARDS, Thomas - "The Arthur of History". in BROMWICH, Rachel; JARMAN, A. O. H.; ROBERTS, Brynley - The Arthur of the Welsh. The Arthurian Legend in Medieval Welsh Literature. $2^{\text {da }}$ ed. Cardiff: University of Wales Press, 2008, pp. 15-32.

CORDO RUSSO, Luciana - The Reception of Medieval French Narrative in Medieval Wales: The Case of Chwedyl Iarlles y Ffynnawn and Cân Rolant. Buenos Aires: Universidad de Buenos Aires, 2015. Tesis Doctoral.

DAVIES, Robert Rees - The Age of Conquest. Wales 1063-1415. Oxford: Oxford University Press.

DAVIES, Sioned - "Performing Culhwch ac Olwen". in LLOYD-MORGAN, Ceridwen (ed.) - Arthurian Literature XXI. Cambridge: Brewer, 2004, pp. 29-51.

EDEL, Doris - "The Arthur of Culhwch and Olwen as a figure of epic-heroic tradition". Reading Medieval Studies 9 (1983), pp. 3-15.

- "The Catalogues in Culhwch ac Olwen and Insultar Celtic Learning". Bulletin of the Board of Celtic Studies 30 (1983), pp. 253-267.

FORD, Patrick K. - "On the Significance of some Arthurian Names in Welsh". Bulletin of the Board of Celtic Studies 30 (1983), pp. 268-273. 
FOSTER, Idris Llewelyn - “Culhwch ac Olwen and Rhonabwy's Dream”. in LOOMIS, Roger. (ed.) - Arthurian Literature in the Middle Ages. Oxford: Clarendon Press, 1959, pp. 31-43.

- "Culhwch ac Olwen". in BOWEN, Geraint - Y Traddodiad Rhyddiaith yn yr Oesau Canol. Llandysul: Gomer, 1974, pp. 64-81.

FULTON, Helen - "Individual and Society in Owein/Yvain and Gereint/Erec". in FALAKY NAGY, Joseph (ed.) - The Individual in Celtic Literatures. Dublin: Four Court Press, 2001, pp. 15-50.

- (ed.) - A Companion to Arthurian Literature. Maldon, MA and Oxford: WileyBlackwell, 2009, pp. 84-101.

GEIRIADUR PRIFYSGOL Cymru [en línea]. Aberystwyth: Canolfan Uwchefrydiau Cymreig a Cheltaidd Prifysgol Cymru, 2014. Disponible en http://geiriadur.ac.uk/gpc/gpc.html

GREEN, Miranda - Animals in Celtic Life and Myth. London y New York: Routledge, 2002.

HALSALL, Guy - Worlds of Arthur. Oxford: Oxford University Press, 2013.

HIGHAM, N. J. - King Arthur. Myth-Making and History. London y New York: Routledge, 2002.

HIGLEY, Sarah - Preiddeu Annwn: The Spoils of Annwn [en línea]. in LUPACK, Alan; LUPACK, Barbara (dir.) - The Camelot Project. Rochester: University of Rochester, 2007. Disponible en http://d.lib.rochester.edu/camelot/text/preiddeu-annwn

JACKSON, Kenneth- "Arthur in Early Welsh Verse". in LOOMIS, Roger (ed.) Arthurian Literature in the Middle Ages. Oxford: Clarendon Press, 1959, pp. 12-19. 
- "The International Popular Tale in Early Welsh: 1". in The International Popular Tale and Early Welsh Tradition. Cardiff: University of Wales Press, 1961, pp. 67-99.

JARMAN, A. O. H. - “The Delineation of Arthur in Early Welsh Verse". in VARTY, Kenneth (ed.) - An Arthurian Tapestry: Essays in Memory of Lewis Thorpe. Glasgow: Glasgow University French Department for the British Branch of the International Arthurian Society, 1981, pp. 1-21.

- "The Arthurian Allusions in the Black Book of Carmarthen". in GROUT, P. et alii (ed.) - The Legend of Arthur in the Middle Ages. Studies presented to A. H. Diverres. Woodbridge: Brewer, 1983, pp. 99-112.

JENKINS, Dafydd - The Law of HywelDda. Llandysul: Gomer, 1986.

JONES, Thomas - "'Pethau nas cyhoeddwyd"”. Journal of the National Library of Wales VII.1 (1951), pp. 62-66.

- "The Early Evolution of the Legend of Arthur" (trad. Gerald Morgan). Nottingham Medieval Studies 8 (1964), pp. 3-21.

KNIGHT, Stephen - Arthurian Literature and Society. New York: Palgrave, 2002.

KÖHLER, Erich - "Le Rôle de la coutume dans les romans de Chrétien de Troyes". Romania 81 (1960), pp. 386-397.

OWEN, Morfydd - “'Arbennic milwr a blodeu marchogyon': Cymdeithas Peredur”. in DAVIES, Sioned; THOMAS, Peter Wynn (ed.) - Canhwyll Marchogyon: Cyddestunoli Peredur. Cardiff: University of Wales Press, 2000, pp. 91-112.

PADEL, Oliver - Arthur in Medieval Welsh Literature. Cardiff: University of Wales Press, 2000.

PASTOUREAU, Michel - "Chasser le sanglier. Du gibier royale à la bête impure: 
histoire d'une dévalorisation". in Une histoire symbolique du Moyen Âge occidental. Paris: Seuil, 2004, pp. 73-88.

PETERS, Edward - The Shadow King. Rex inutilis in Medieval Law and Literature. New Haven y London: Yale University Press, 1970.

RADNER, Joan - "Interpreting Irony in Medieval Celtic Narrative: The Case of Culhwch ac Olwen". Cambrian Medieval Celtic Studies 16 (1988), pp. 41-59.

REGNIER-BOHLER, Danielle - "Préface". in RÉGNIER-BOHLER, Danielle (dir.) La légende arthurienne: le Graal et la Table Ronde. Paris: Laffont, 1990, pp. I-LII.

ROBERTS, Brynley - "Geoffrey of Monmouth and Welsh Historical Tradition". Nottingham Medieval Studies 20 (1976), pp. 29-40.

- "Tales and Romances". in JARMAN, A. O. H.; HUGUES, Gwilym R. - A Guide to Welsh Literature, vol. 1. Swansea: Cristopher Davies, 1976, pp. 203-243.

- "The Welsh Romance of the Lady of the Fountain (Owein)". in GROUT, P. et alii (ed.) - The Legend of Arthur in the Middle Ages. Studies presented to A. H. Diverres. Woodbridge: Brewer, 1983, pp. 170-82.

- "Culhwch ac Olwen, the triads, saints' lives". in BROMWICH, Rachel; JARMAN, A. O. H.; ROBERTS, Brynley - The Arthur of the Welsh. The Arthurian Legend in Medieval Welsh Literature. $2^{\text {da }}$ ed. Cardiff: University of Wales Press, 2008, pp. 73-95.

RODWAY, Simon - "The Date and Authorship of Culhwch ac Olwen: A Reassessment”. Cambrian Medieval Celtic Studies 49 (2005), pp. 21-44.

SIMS-WILLIAMS, Patrick - "The Early Welsh Arthurian Poems". in BROMWICH, Rachel; JARMAN, A. O. H.; ROBERTS, Brynley - The Arthur of the Welsh. The Arthurian Legend in Medieval Welsh Literature. $2^{\text {da }}$ ed. Cardiff: University of Wales Press, 2008, pp. 33-71. 
- "The Irish Elements in Culhwch and Olwen". in Irish Influence on Medieval Welsh Literature. Oxford: Oxford University Press, 2010, pp. 134-187.

STURZER, Ned - “The Purpose of Culhwch and Olwen”. Studia Celtica 39 (2005), pp. 145-167.

\section{COMO CITAR ESTE ARTIGO}

\section{Referência electrónica:}

CORDO RUSSO, Luciana - "Culhwch ac Olwen como texto de transición de la materia artúrica". Medievalista 22 (Julho-Dezembro 2017). [Em linha] [Consultado dd.mm.aaaa]. Disponível em http://www2.fcsh.unl.pt/iem/medievalista/MEDIEVALISTA22/russo2204.html ISSN 1646-740X.

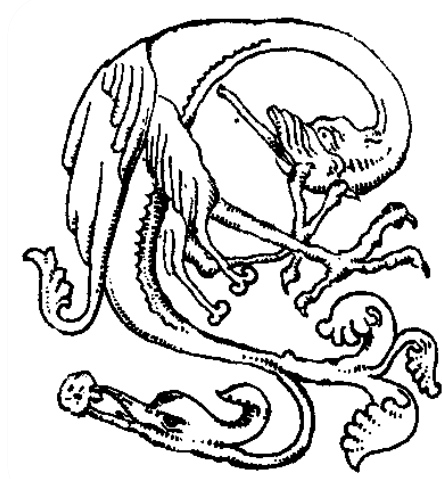

